\title{
Editorial: New Review Editors
}

This editorial introduces Julia Johnson and Joanna Bornat as the new Review Editors of the journal. They are both full-time academic staff at the School of Health and Social Welfare at The Open University $(\mathrm{OU})$ in Milton Keynes to the north of London. They are very well known among British social gerontology and social welfare researchers and have exceptional writing and editorial experience - even more than the high average for Open University 'distance teachers'. Joanna has been joint editor of Oral History for twenty-five years and, with Julia, has been a co-editor of Generations Review, the other journal of the British Society of Gerontology.

The OU School of Health and Social Welfare has a long history of involvement in ageing research and teaching. In I979, it launched the pioneering undergraduate course, 'An ageing population', and this was followed by successive courses and teaching packs on ageing which over 20 years reached thousands of students, practitioners and professionals. Most recently, Julia and Joanna have jointly chaired the production of a new Open University course, 'Care, welfare and community'. Their research base is in the School's Centre for Ageing and Biographical Studies where, between them, they have developed several fields of study. Julia's research interests relate to policy and practice in residential and community care and to the social construction of care and care relationships. She has also been involved in a major project on medicines and older people, and is interested in the use of diaries to study the everyday lives of older people. Joanna's interests include late-life reminiscence and remembering in health and social care contexts, family change and older people and, most recently, the contribution of overseas doctors to the development of geriatric medicine as a specialty in the United Kingdom. She has a special interest in biographical and oral history research methodologies. Julia and Joanna are currently developing joint research on moving and handling in later life.

Turning to their plans for the review section, the first priority is to reestablish prompt publication of book reviews of major and notable titles in social gerontology, with selective coverage of related fields in gerontology. Over the years the review section has offered not only conventional book reviews but also selective abstracts, review essays and symposia, progress reports and 'ageing updates'. Joanna and Julia have already made plans to revive review articles. They are inviting authors with appropriate 
expertise to prepare concise articles that critically review recent research and publications on defined themes or issues. They are also keen to reinstate review symposia, in which a notable publication is reviewed from different angles by several reviewers. Such symposia are an exceptionally valuable way of encouraging communication within and between disciplines, and of opening up the review section to cross-disciplinary perspectives and debate.

Their ambition is that the review section of Ageing \& Society continues to be found informative and stimulating by readers from academic, professional and practice backgrounds as well as older people themselves. They hope to add to the journal's reputation for its multi-disciplinary and international content with an eclectic mixture of material and views that are presented in lively and accessible ways. With all this in mind, they invite readers and subscribers to send by email suggestions for reviews and to offer to write reviews. Their contact details will be found on the inside front cover. A 'guide to reviewers' on style, format and submission matters for all components of the review section of the journal is available.

\section{TONY WARNES}

